\title{
Assessment of cervical neck lesions with contribution of fine needle aspiration cytology: a retrospective study in western Uttar Pradesh region
}

\author{
Sudhakar K.V.K. ${ }^{1}$, Khajuria A. ${ }^{2}$, Sen M. ${ }^{3}$ \\ ${ }^{1}$ Dr. Kovuri Venkata Krishna Sudhakar, Associate Professor, ${ }^{2}$ Dr. Anuj Khajuria JR, ${ }^{3}$ Dr. Moumita Sen, JR; both authors \\ are attached with Department of ENT, Teerthankar Mahaveer Medical College and Research Centre, Moradabad, Uttar \\ Pradesh India.
}

Corresponding Author: Dr. Kovuri Venkata Krishna Sudhakar, Associate Professor, Department of ENT, Teerthankar Mahaveer Medical College and Research Centre, Moradabad, Uttar Pradesh India. E-mail: sudhakarkovuri@yahoo.com

\begin{abstract}
Introduction: Cervical masses have probable spectrum of nonspecific inflammation to malignancy and tuberculosis. The object of the present study was to assess a number of cervical neck mass with the role of FNAC to diagnose these lesions. Materials and Methods: The characteristics were noted on pre-outlined questionnaire as regarding local investigation findings, laboratory and history of cases and patients' personal details. Analysis of every case was depending upon cytomorphology and clinical evaluation as cytological findings. Results: Out of 520 patients there were 254 (48.84\% male and 266 were female cases. Thyroid lesions were found excessive in female (85.91\%) compare to male (14\%). Occurrence of lymph node was found $56.12 \%$ in male cases and $43.87 \%$ in female cases, which were slightly more in male patients. The prevalence of salivary gland lesion was found more in male $(55 \%)$ compare to female $(45 \%)$. Conclusion: FNAC is useful investigation in diagnosis of cervical masses.
\end{abstract}

Keywords: Cervical neck Lesions, FNAC, Malignancy and tuberculosis

\section{Introduction}

Basis of cervical masses has probable spectrum of nonspecific inflammatory reaction to malignancy and tuberculosis. The diagnosis of the etiology has utmost significance because of the dealing of these varied lesions is very diverse, for that a definitive analyzer tool is necessitate which is low - cost and expeditious. To acquire tissue and cell particles the pathologist has apply needle aspiration to diagnose a fundamental pathology [1]. An inexpensive tactful and fixed tool is Fine Needle Aspiration Cytology to determine cervical lesions [1].

Followed along an absolute head and neck investigation the assessment of a case with cervical mass should always undertake aspiration cytology. The FNAC appreciated in the investigation of infective swellings although it is also clinically useful in neoplastic lesion $[2,3]$. It becomes the chief analyzer with leading in assessment of swollen nodes in the region of neckline

Manuscript received: $30^{\text {th }}$ July 2019

Reviewed: $10^{\text {th }}$ August 2019

Author Corrected: $15^{\text {th }}$ August 2019

Accepted for Publication: $19^{\text {th }}$ August 2019 from the last two decades and exactness, less disruptive nature of method and low - cost. As chief screening investigation for nodules of thyroid in adults the FNAC has been benefit ing with great accuracy, [4-6] and it also got high value with non-thyroid lump.

Fine needle aspiration of the lump can be implementing if the physical investigation does not describe the mass in cervical neck region [7]. In the examination of lymphadenopathy, the performance of FNAC has earlier been proved according to the various research [8-12]. following by lymphomas and malignant metastatic accumulation the most regular origin of lymphadenopathy in our background exists an inflammatory response to a bacteriological task. Predominantly speaking, the component of etiology for these lumps make a vast list as they tend to be appraised in the form of as malignant metastases tuberculosis and reactive. The utmost usual source of granulo-matous lymphadenitis in our country is $\mathrm{M}$. tuberculosis. Overall for the majority of lesion, the reactive infective condition is accountable [13-15]. 


\section{Original Research Article}

The Object of the present study was to assess a number of cervical neck mass with the role of FNAC to diagnose these diseases.

\section{Material and Method}

The current research is done in the ENT department at, Teerthanker Mahaveer Hospital and Medical College Moradabad, Uttar Pradesh India and type of the research is retrospective, and carried out from February 2016 to July 2018. Total 560 cases who had FNAC masses wear recruited in this study. Earlier to conduct FNAC the characteristics clinical detection was noted, and additional Radiological determination were also recorded for interrelationship.

The process of fixation through hemato-xylin-eosin stains and preparation of smear is done after aspiration.
The characteristics were noted on pre-outline questionnaire as regarding local investigation findings, laboratory and history of cases and patients' personal details.

All the data were analyzed using Excel software and data were noted on excel sheet. The materials which was taken by aspiration was smeared into glass slides with equally grounding, dried out smears by air as MayGrunwaldGiemsa stain and smear through alcohol stable (95\%) used for Papan-icolaou stain, and Ziehl Neelsen stain also used whenever its needed.

Analysis of every case was depending upon cytomorphology and clinical evaluation as cytological findings. The case, which was investigated by FNAC as lymphoma, a lymph node biopsy was made.

\section{Results}

The present study recruited 560 cases with single, collective, one sided; both sided and centrally placed neck mass. Both genders with age ranged from 10 to 60 years were included. The range of median age were 39 years and most of the patients were $25-40$ years of age out of $100 \%$ cases $7.14 \%$ of cases aspirate was unsatisfactory so they were excluded from the study.

Out of 520 patients there were 254 (48.84\% male and 266 were female cases. Thyroid lesions were found excessive in female $(85.91 \%)$ compare to male $(14 \%)$. Occurrence of lymph node was found $56.12 \%$ in male cases and $43.87 \%$ in female cases, which were slightly more in male patients. (Table 1.) The prevalence of salivary gland lesion was found more in male (55\%) compare to female (45\%). Other lesion like soft-tissue and other lesion remained also found somewhat more in male subjects compare to female. Prevalence of lesion in neck area was observed high as comparisons with the head region. In the lesion of neck, the cervical lymph node was commonly found whereas in head region parotid lesion was found very commonly (Table 2). Patient's distribution conferring to the inflammatory and neoplastic abrasion was presented in Table 3.

Table-1: Gender wise and region wise distribution lesions present in neck.

\begin{tabular}{|c|c|c|c|c|c|}
\hline Site & \multicolumn{2}{|c|}{ Male } & \multicolumn{2}{c|}{ Female } & Total \\
\hline & No. of cases & $\mathbf{\%}$ & No. of cases & \% & \\
\hline Lymph node & 165 & 56.12 & 129 & 43.87 & 294 \\
\hline Thyroid gland & 20 & 14.08 & 122 & 85.91 & 142 \\
\hline Salivary gland & 11 & 55 & 9 & 45 & 20 \\
\hline Soft tissue \& miscelleneous & 41 & 64.06 & 23 & 35.93 & 64 \\
\hline Total & $\mathbf{2 3 7}$ & $\mathbf{4 5 . 5 7}$ & $\mathbf{2 8 3}$ & $\mathbf{5 4 . 4 2}$ & $\mathbf{5 2 0}$ \\
\hline
\end{tabular}

Table-3: Patient's distribution conferring to the inflammatory and neoplastic disease

\begin{tabular}{|c|c|c|c|}
\hline \multirow{2}{*}{ Tissue } & \multirow{2}{*}{ Infection } & \multicolumn{2}{|c|}{ Neoplastic } \\
\cline { 3 - 4 } & & Benign & Malignant \\
\hline Lymph node & $176(67.43)$ & $43(23.24)$ & $58(78.37)$ \\
\hline Thyroid & $42(16.09)$ & $79(42.70)$ & $4(5.40)$ \\
\hline Salivary gland & $18(6.89)$ & $30(16.21)$ & $12(16.21)$ \\
\hline Soft tissues \& miscellaneous & $25(9.57)$ & $33(17.83)$ & Nil \\
\hline Total & $\mathbf{2 6 1}$ & $\mathbf{1 8 5}$ & $\mathbf{7 4}$ \\
\hline
\end{tabular}


Out of 64 cases it was observed that $15 \%$ case of Benign Spindle cell tumor, 19 Percent of Benigncy stic Lesion, 6 percent of brachial cyst and 31 percent of sebaceous cyst in Soft tissue \& miscellaneous lesion. Distribution of case according to the various lesions were shown in Figure 1, 2 and 3.

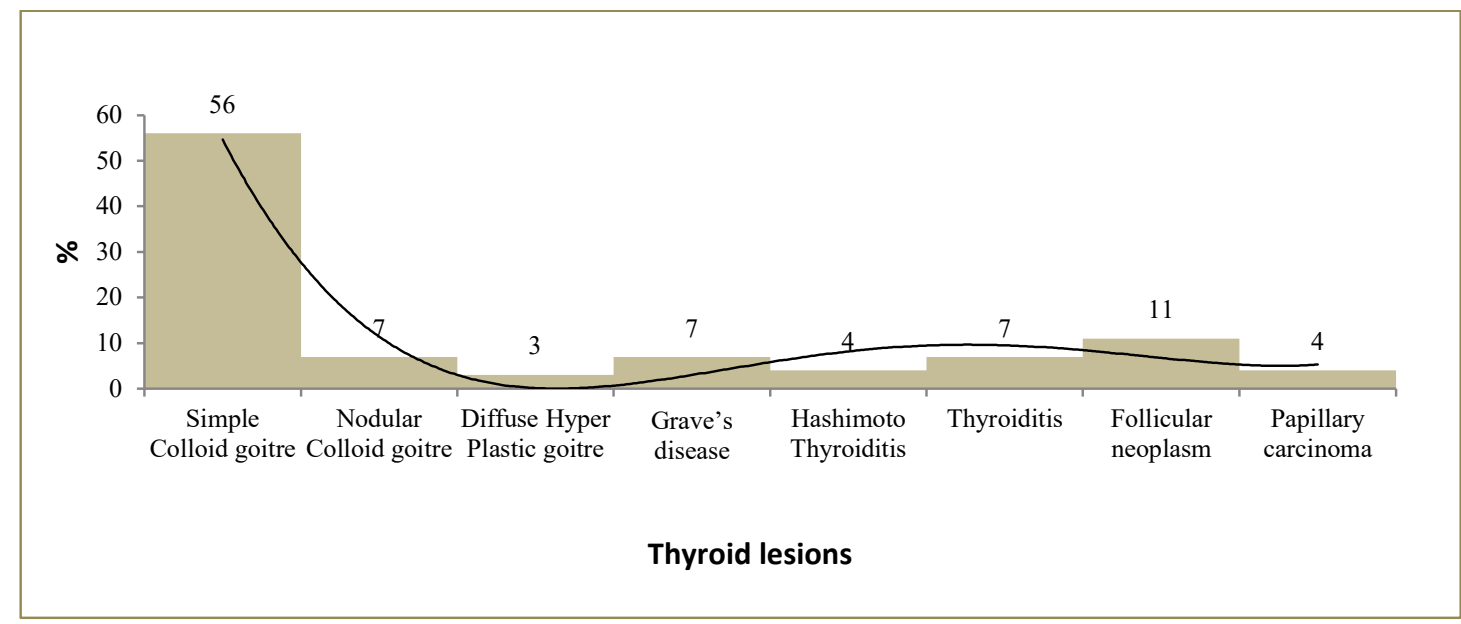

Figure 1: Distribution of cases according to the thyroid lesions

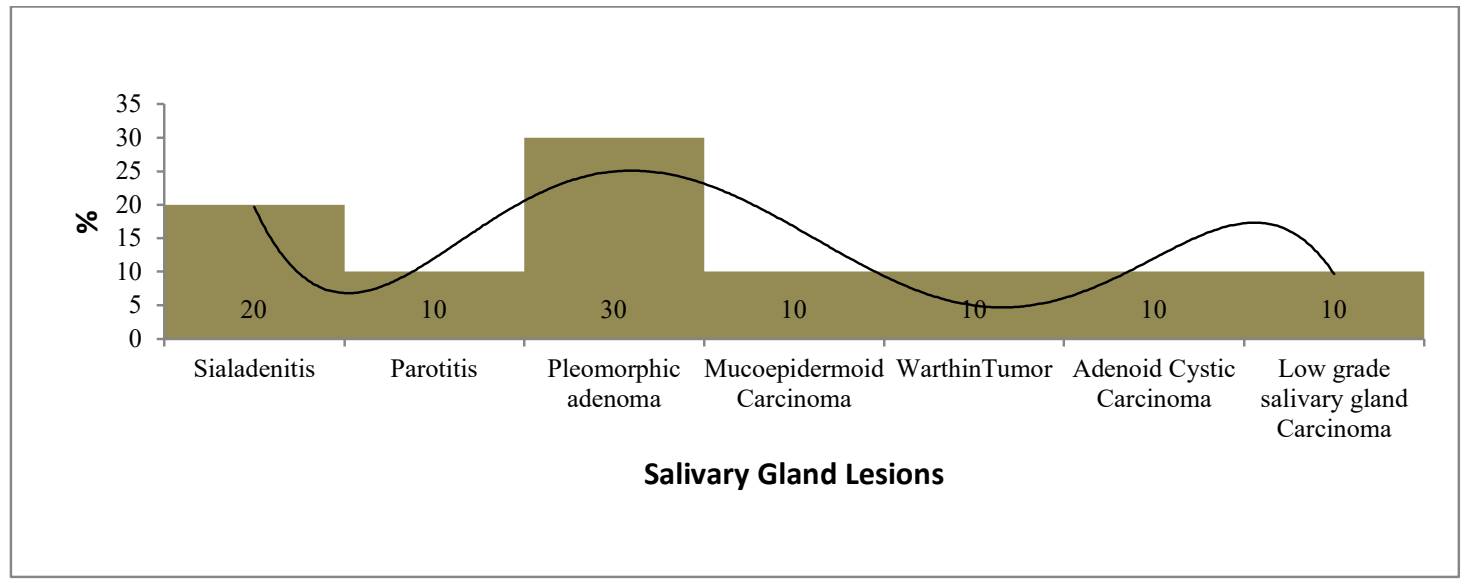

Figure 2: Distribution of cases according to the salivary gland lesions

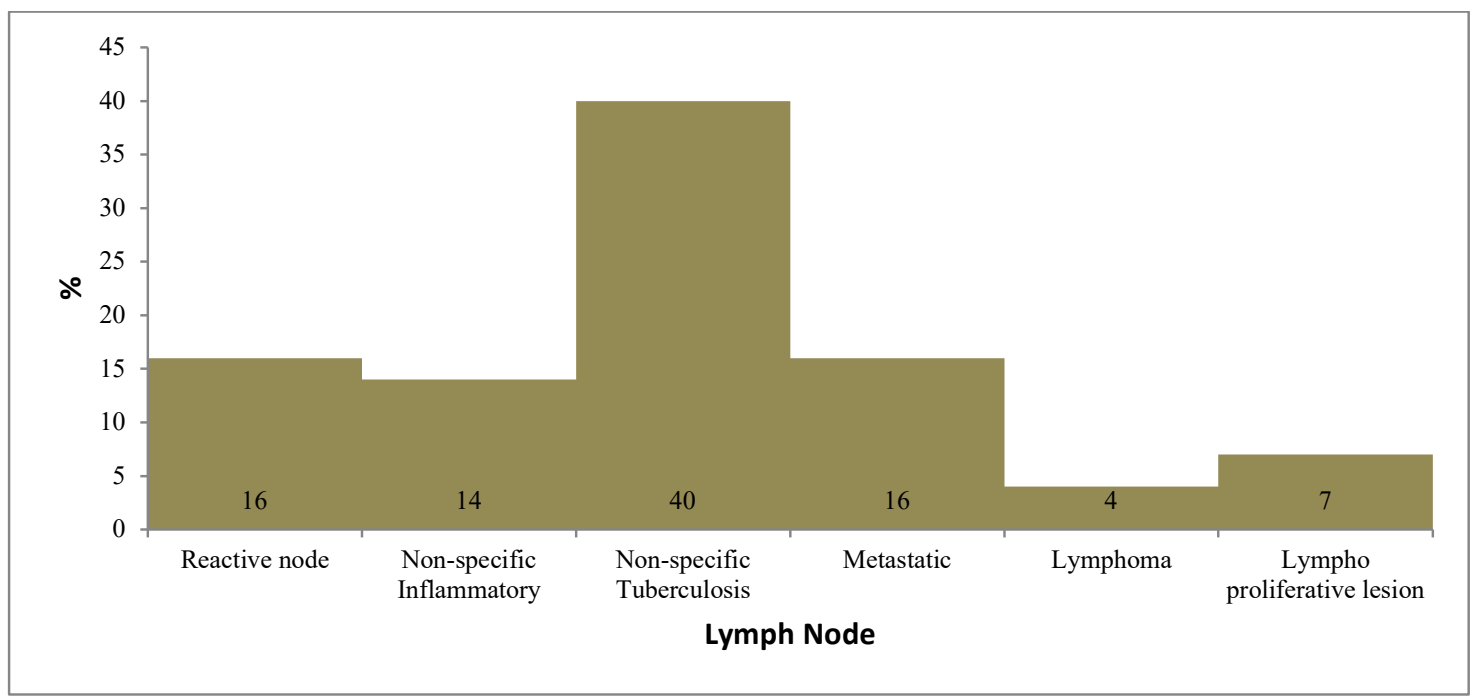

Figure 3: Distributes of case according to the lymph node lesions 


\section{Discussion}

When the achieved result of the present study was compared with other studies, it was observed that the work done by Jasani et al,[16] there be present 54\% male and rests be there females i.e. $46 \%$ [16]. 25 to 35 years aged were the one to be shown huge occurrence and pervasiveness. In the present study out of 520 patients there were $254(48.84 \%) 0$ male and 266 were female cases.

Thyroid lesions were found excessive in female $(85.91 \%)$ compare to male. More incidences noted in the present study were in 25 to 40 years old. The present study observed occurrence of lymph node was found $56.12 \%$ in male cases and $43.87 \%$ in female cases, which were slightly more in male patients.

The prevalence of salivary gland lesion was found more in male $(55 \%)$ compare to female $(45 \%)$. which is same as Rathod GB et al study [17]. William [18] identified that the most common period in the midst of male subjects was sixty years and females fifty-five years were more commonly affected with the lymph node disease. in India and other Western countries, a purpose possibly will be communal participation of lymph nodes by Koch's contamination.

In resulting of minimize communal periods as twentythree years midst females and thirty-three years amongst male, tuberculosis affects in children's and grown person.

Gupta AK [19] found out that the engrossment of lymph node of neck region were (62\%), supra-clavicular (16\%) and others were $(22 \%)$. our work confirmed that the contribution of nodes were $79 \%$ cervical, $13 \%$ additional and supraclavicular (4\%).

Existing work exposed that lymph node with cervical group was most common location. On the anatomical basis and embryonically foremost salivary glands is thoroughly linked with lymphoid organ.

A localize swelling and disease with growth of tumors distressing peri-salivary group of nodes come into the medical discrepancy identification of tumors of salivary gland.

In all other studies the thyroid mass which was seen was most commonly was colloid goitre and same was found in the present study that there were high pervasiveness of goitre. May be more figure of feminine subjects in present work exists reason to justify. Sialade-nitis remained the communal with parotid diseases in present work encompassing (53.84\%) tracked by pleomorphic growth (30\%) and cystic laceration, Warthin's cancer, monomorphic growth and malignant abrasions (10\%). It can be compared to various other research and pleomorphic adenoma

comprise the greater number of tumors of salivary gland [20]. only One case with carcinoma of mucoepidermoid, was identified by FNAC which were after on assured by histopathological examination. However, elucidation of FNAC from the salivary glands lesions is arduous cyto-pathological skill for various risk and difficulties [21] while fewer of these issues are same to that experience with exposition from any supplementary histo-logical things as well as these exist because of the different too hetero-geneous types of neoplasia of mixed gland.

Additional quandaries are characteristic to FNAC, ambiguity for instance to the region or soft tissue essentially extracted, less substance and the deficiency of constitutional outline in substance smears associated through histo-logical segments [22].

\section{Conclusion}

The mass in the neck region is actually so common presentation to ENT specialist. Several age groups from infancy to elderly may be affected with this.

Frequency of diseases with thyroid region considerably was greater in male cases as compared with female cases, whereas occurrence of some, like lesions of salivary gland, lymph node, soft tissue and supplementary lesions remained slight greater in male.

Assessment of this type of case is essential directive to get the exclusive and conclusive diagnosis for pass up avoidable operative involvements and ease transfer of patients to advanced centers if necessary. FNAC is safe and sound, simple procedure for diagnosis. No specific training is required, save period, funds, and clinic space.

\section{What the study adds to the existing knowledge?}

Assessment of this type of case is essential directive to get the exclusive and conclusive diagnosis for pass up avoidable operative involvements and ease transfer of patients to advanced centers if necessary. 


\section{Original Research Article}

\section{Author's contribution}

Dr. Kovuri Venkata Krishna Sudhakar: Concept, study design and manuscript preparation

Dr. Anuj Khajuria: Concept, study design and manuscript preparation

Dr. Moumita Sen: Concept, study design and manuscript preparation

\section{Funding: Nil, Conflict of interest: Nil Permission from IRB: Yes}

\section{References}

1. Lau SK, Wei WI, Hsu C, Engzell UC. Fine needle aspiration biopsy of tuberculous cervical lymphadenopathy. Aust N Z J Surg. 1988;58(12):947-950. doi:10. 1111 j. 1445-2197.1988.tb00098.x

2. Rahman MA, Biswas MMA, Sikder AM. Scenario of fine needle aspiration cytology of neck masses in a tertiary care hospital. J Enam Med Col. 2011;1(1):8-14. doi: https://doi.org/10.3329/jemc.v1i1.11131

3. Advani SK, Aqil S, Dahar A. Role of fine needle aspiration cytology (FNAC) in neck masses/cervical lymphadenopathy. Pakistan J Chest Med. 2015;14(3).

4.Pitman MB, Abele J, Ali SZ, Duick D, Elsheikh TM, Jeffrey RB, et al. Techniques for thyroid FNA: a synopsis of the National Cancer Institute Thyroid FineNeedle Aspiration State of the Science Conference. Diagn Cytopathol. 2008;36(6):407-424. doi: 10.1002/ dc. 20829.

5. Cibas ES, Alexander EK, Benson CB, de Agustín PP, Doherty GM, Faquin WC, et al. Indications for thyroid FNA and pre-FNA requirements: a synopsis of the National Cancer Institute Thyroid Fine-Needle Aspiration State of the Science Conference. Diagn Cytopathol. 2008; 36 (6): 390-399.doi: 10.1 002/dc. 20827.

6. Abati A. The National Cancer Institute Thyroid FNA State of the Science Conference: "Wrapped up". Diagn Cytopathol. 2008; 36(6): 388-89. doi: 10. 1002/dc. 20850.

7. Göret CC, Göret NE, Özdemir ZT, Özkan EA, Doğan M, Yanık S, et al. Diagnostic value of fine needle aspiration biopsy in non-thyroidal head and neck lesions: a retrospective study of 866 aspiration materials. Int J Clinic Experiment Pathol. 2015;8(8): 8709-8716.
8. Steel BL, Schwartz MR, Ramzy I. Fine needle aspiration biopsy in the diagnosis of lymphadenopathy in 1,103 patients. Role, limitations and analysis of diagnostic pitfalls. Acta Cytol. 1995;39(1):76-81.

9. Lioe TF, Elliott H, Allen DC, Spence RA. The role of fine needle aspiration cytology (FNAC) in the investigation of superficial lymphadenopathy; uses and limitations of the technique. Cytopathol. 1999;10(5): 291-297. doi: https://doi.org/10.1046/j.1365-2303.1999. 00183.x

10. Pandit AA, Candes FP, Khubchandani SR. Fine needle aspiration cytology of lymph nodes. J Postgrad Med. 1987;33(3):134-136.

11. Prasad RR, Narasimhan R, Sankaran V, Veliath AJ. Fine-needle aspiration cytology in the diagnosis of superficial lymphadenopathy: An analysis of 2,418 cases. Diagnos Cytopathol. 1996;15(5):382-386.

12. Paul PC, Goswami BK, Chakrabarty S, Giri A, Pramanik R. Fine needle aspiration cytology of lymph nodes-An institutional study of 1448 cases over a fiveyear period. J Cytol. 2004;21:187-190.

13. Indian Council of Medical Research, Tuberculosis in India - A sample survey, 1955-58. Special Report Series No. 34, New Delhi:1959.

14. Dandapat MC, Mishra BM, Dash SP, Kar PK. Peripheral lymph node tuberculosis: a review of 80 cases. Br J Surg. 1990;77(8):911-922. doi:10.1002/bjs. 1800770823

15.Jawahar MS, Sivasubramanian S, Vijayan VK, Ramakrishnan CV, Paramasivan CN, Selvakumar V, et al. Short course chemotherapy for tuberculous lymphadenitis in children. BMJ. 1990;301(6748):359362. doi:10.1136/bmj.301.6748.359

16. Jasmin HJ, Hetal VV, Parul NV, Dipmala P, Yash $\mathrm{S}$, Nisarg S, et al. Retrospective study of fine needle aspiration cytology of head and neck lesion in tertiary care hospital. Int J Biomed Advan Res. 2013;4(4).

17. Rathod GB, Parmar P. Fine needle aspiration cytology of swellings of head and neck region. Indian J Med Sci. 2012;66(3-4):49-54. doi: 10.4103/0019-5359. 110896.

18. Betsill WL, Hajdu SI. Percutaneous aspiration biopsy of lymph nodes. Am J Clin Pathol. 1980;73 (4):471-479. doi:10.1093/ajcp/73.4.471 
19. Gupta AK, Nayar M, Chandra M. Reliability and limitations of fine needle aspiration cytology of lymphadenopathies. An analysis of 1,261 cases. Acta Cytol. 1991;35(6):777-783.

20. Evans RW, Cruickshank AH. Epithelial tumours of the salivary glands. Major Probl Pathol. 1970;1:1-299.
21. Young JA. Diagnostic problems in fine needle aspiration cytopathology of the salivary glands. J Clin Pathol. 1994;47(3):193-198. doi:10.1136/jcp.47.3.193

22. Eveson JW. Troublesome tumours 2: borderline tumours of salivary glands. J Clin Pathol. 1992;45(5): 369-377. doi:10.1136/jcp.45.5.369

\section{How to cite this article?}

Sudhakar K.V.K, Khajuria A., Sen M. Assessment of cervical neck lesions with contribution of fine needle aspiration cytology: a retrospective study in western Uttar Pradesh region. Trop J Ophthalmol Otolaryngol.2019;4(4):285-290. doi:10.17511/jooo.2019.i04.05 